\title{
Recognition and management of hereditary colorectal cancer syndromes
}

\author{
M. Herráiz ${ }^{1,2}$ and M. Muñoz-Navas ${ }^{1}$ \\ ${ }^{1}$ Service of Digestive Diseases and ${ }^{2}$ Unit of Prevention and High-risk Gastrointestinal Cancer Clinic. \\ Clínica Universidad de Navarra. Pamplona, Spain
}

\begin{abstract}
Over 1.900 colorectal tumors will arise in association with a hereditary colorectal cancer syndrome in Spain in 2009.

The genetic defects responsible for the most common syndromes have been discovered in recent years.

Genetic testing helps diagnose affected individuals and allows identification of individuals at-risk.

Colonoscopy and prophylactic colectomy decrease colorectal cancer incidence and overall mortality in patients with hereditary colon cancer.

Extracolonic tumors are frequent in these syndromes, so specific surveillance strategies should be offered.
\end{abstract}

Key words: Familial adenomatous polyposis. Lynch syndrome. MYH-associated polyposis. Hereditary colon cancer.

Herráiz M, Muñoz-Navas M. Recognition and management of hereditary colorectal cancer syndromes. Rev Esp Enferm Dig 2009; 101: 125-132.

\section{INTRODUCTION}

In 2009 , it is estimated that around 38,000 people (1) in Spain will be diagnosed with colorectal cancer (CRC). Among these cases, more than $15 \%$ will exhibit familial

Received: 04-02-09.

Accepted: 04-02-09.

Correspondence: Maite Herráiz. Servicio de Aparato Digestivo. Unidad de Prevención y Consulta de Alto Riesgo de Tumores Digestivos. Clínica Universidad de Navarra. Avda. Pio XII, 36. 31008 Pamplona, Spain. e-mail: mherraizb@unav.es clustering, and over 1,900 tumors (5\%) will arise in association with a hereditary colorectal cancer syndrome. The most common hereditary colon cancer syndromes are: Familial Adenomatous Polyposis (FAP), attenuated FAP (AFAP), MYH associated polyposis (MAP), and Lynch syndrome, also known as Hereditary Non-Polyposis Colorectal Cancer syndrome (HNPCC) (2).

During the last two decades, the most important advancement has been the identification of the genes that underlie these syndromes. This has permitted more accurate classifications of the various syndromes based upon genetic criteria, and consequently this has resulted in more tailored management strategies based on these criteria (3). The management of individuals with hereditary colon cancer or at-risk for hereditary colon cancer is dramatically different, so recognizing these syndromes is critical. Specifically, surveillance strategies for colon and extra-colonic tumors as well as surgical approaches (4) for the prevention and treatment of cancer reflect the heightened risks.

This review is focused on current treatment strategies in hereditary colon cancer. It is important to recognize that "treatment" includes not only management of already diagnosed cancers but also to prevention of cancer in these high-risk populations. We first briefly summarize the major clinical features of each syndrome, including pattern of inheritance and penetrance, age at diagnosis and associated extra-colonic tumors.

\section{Familial adenomatous polyposis and attenuated FAP}

FAP is the most common adenomatous polyposis syndrome. Its prevalence is 1:5.000-10.000, with a uniform worldwide distribution, affecting both genders equally (5). Inherited in an autosomal dominant manner with a virtually penetrance of $100 \%$, it is caused by a germline mutation in the Adenomatous Polyposis Coli (APC) tu- 
mor suppressor gene on chromosome 5q21 (6). In 15$20 \%$, the cases are "de novo" without clinical or genetic evidence of FAP in the parents (7). Recent studies indicate the presence of mosaicism in approximately $15 \%$ of such cases $(8,9)$.

Classic FAP is characterized by the development of hundreds to thousands of colorectal adenomas starting during the teenage years. Those polyps will inevitably progress to colorectal cancer by the age of 40 years. In addition, multiple gastric fundic gland polyps can develop. Duodenal, peri-ampullary, or ampullary adenomas ultimately develop in nearly all FAP patients at a median age at diagnosis of 38 years (10). Duodenal lesions may progress over time with an estimated cumulative risk of duodenal adenocarcinoma of $10 \%$ by the age of 60 years (11), making it the second most common malignancy in FAP.

Associated extra-intestinal features include desmoids tumors, congenital hypertrophy of the retinal pigment epithelium, epidermoid cysts, osteomas and thyroid cancer, primarily the papillary variant (12). The majority of desmoids tumors occur within 5 years after abdominal surgery (13). Of note, desmoids tumors rank as the second cause of mortality behind metastatic carcinoma in FAP patients (14). A family history of desmoids and germline mutations beyond codon 1444 have been identified as independent risk factors for desmoids $(13,15)$.

Attenuated FAP is a phenotypically distinct variant of FAP in which patients present with fewer than 100 adenomas, more proximal colonic locations of polyps, and an approximate delay of 15 years in the age of CRC onset. There are, however, no differences in upper gastrointestinal tract lesions. This phenotype has been consistently linked to APC germline mutations located at the 5' end (proximal to codon 157) or the 3 ' end of the gene (distal to codon 1596) (5).

\section{MYH associated polyposis}

Mutations in the human MutY homologue $(M Y H)$ gene can also result in multiple colorectal adenomas. The syndrome, designated MYH associated polyposis (MAP), is unique in that it is inherited in an autosomal recessive manner. The $M Y H$ gene, located on the short arm of chromosome 1 , is a DNA glycosylase that participates in the base excision repair process by correcting mutations from oxidative damage. The Y165C and G382D missense mutations account for the majority (80\%) of all MYH mutations in Caucasians (16).

The MAP syndrome is categorized as an oligopolyposis syndrome and phenotypically resembles AFAP with polyps frequently numbering less than 100. In European populations, approximately $25 \%$ of individuals with more than 10 adenomatous polyps carried biallelic germline $M Y H$ mutations $(16,17)$. However, there is also a subset that displays features of classic FAP, as biallelic mutations in $\mathrm{MYH}$ are responsible for up to $7.5 \%$ cases of APC-negative classic FAP (16). Interestingly, these individuals resemble cases of FAP with "de novo" APC mutations, as there is no evidence of polyposis in either parent.

The precise colon cancer risk associated with bi-allelic MYH mutations has not yet been established, but most evidence points to a high penetrance approaching the $100 \%$ level appreciated in FAP. The mean age at colon cancer diagnosis is 50 years (17). The implication of a single $M Y H$ mutated allele remains unclear, but some evidence suggests that these individuals are at a modestly increased risk (3fold) of colorectal cancer compared with the general population (18). Thus far, there is no evidence of a direct causal relationship with extracolonic tumors, but some features of FAP including fundic gland polyps and duodenal adenomas have been reported $(16,17,19,20)$.

\section{Lynch syndrome}

Lynch syndrome is the most common hereditary colon cancer syndrome and accounts for about 2-3\% of all colorectal cancer cases (21). Also recognized as HNPCC, Lynch syndrome is due to mutations in a DNA mismatch repair (MMR) gene ( $M L H 1, M S H 2, M S H 6$ or $P M S 2)$ and exhibits an autosomal dominant inheritance pattern with a lifetime risk of colon cancer between $60-80 \%(22,23)$. Due to this genetic alteration, nearly all colorectal tumors that arise in individuals with Lynch syndrome display a distinctive molecular signature called microsatellite instability (MSI) (24). MSI testing can serve as a useful screening test for HNPCC, but it should be recognized that MSI is also found in up to $15 \%$ of sporadic tumors (24). Because the sensitivity of germline genetic testing in Lynch syndrome approximates $70 \%$, families who have MSI-positive tumors and a consistent family history but no germline mutation can still be considered to have the Lynch syndrome (25).

Colorectal cancers are diagnosed at an average age of 45 years (26) and are typically located in the proximal colon $(70 \%)(21)$. Synchronous and metachronous tumors are commonly seen. Moreover, a particular set of histopathological features has been associated with these tumors: mucinous and signet-ring differentiation, medullary growth pattern, poor differentiation, Crohn'slike lymphocytic infiltration and the presence of tumorinfiltrating lymphocytes.

Many extracolonic tumors have been associated with Lynch syndrome. The uterus is the most common site outside of the colon. In fact, the risk of endometrial cancer equals or exceeds the risk for colon cancer among women with Lynch syndrome (22). Other tumors consistently reported in this syndrome are gastric, ovarian, small bowel, bladder, urinary tract, biliary tract, brain and skin (sebaceous adenomas or carcinomas and keratoacanthomas) (27). 


\section{GENETICS AND DIAGNOSIS}

The management and treatment of hereditary colon cancer first depends upon the accurate diagnosis of each syndrome. The most important advance in this aspect has been the introduction of genetic testing for germline DNA alterations. In spite of its clinical value, genetic testing is limited by its cost and concerns regarding privacy. Patients may be reluctant to be identified as a carrier of a cancer-causing genetic mutation that potentially may limit their ability to obtain insurance or employment (28). Who to test and for which syndrome to test remain the key issues.

Genetic testing for hereditary colon cancer analyzes human DNA from a blood sample in order to detect alterations in a gene known to cause a particular disorder. This can be accomplished by directly examining the DNA (sequence analysis and deletion/duplication analysis) or looking at markers co-inherited with a diseasecausing gene (linkage testing).

A positive genetic testing in a symptomatic individual is considered "diagnostic" and confirms the suspected genetic disorder. In addition, "predictive" genetic testing can be offered to asymptomatic individuals with a family history of hereditary cancer to provide risk assessment. In general, genetic testing of an affected individual is necessary for testing of any other family members to be interpretable. Once a mutation has been identified in a family, testing is technically straightforward (3). Genetic counseling is strongly recommended prior to genetic testing (3).

Classic FAP has striking clinical phenotype. A diagnosis can be comfortably made based upon clinical features, but genetic testing plays a critical role for risk assessment in asymptomatic family members (3). Individuals without a family history of polyposis -so-called "de-novo" cases of FAP- who have a nondiagnostic or equivocal (variant of uncertain significance) result for APC gene testing should be tested for MYH.

Patients with adenomatous oligopolyposis (between 10-100 adenomas) represent a challenge. This may very well represent either AFAP or MAP, and differentiating between these two is important in formulating an appropriate management strategy, particularly in terms of family counseling, extracolonic tumor surveillance and chemoprevention (3). A positive germline test can establish either diagnosis, but in the absence of that information other clinicopathological features might be useful. A family history suggestive of an autosomal dominant inheritance will point to AFAP. The absence of fundic gland polyps and duodenal adenomas in upper GI endoscopy will do MAP diagnosis more likely.

The identification of Lynch syndrome is much less straightforward due to the absence of florid polyposis. Three lines of information are considered for establishing the diagnosis: family history, molecular tumor characteristic (MSI) and germline DNA testing. A family history indicative of Lynch syndrome is defined by the Amsterdam criteria (I and II, Table I). It is important to recognize that although a family history of colorectal cancer is helpful when present, its absence does not exclude Lynch syndrome. The Bethesda guidelines (Table I) were formulated as a set of less restrictive criteria that indicate which tumors should be tested for MSI. A discussion of the different diagnostic algorithms and their rationale when evaluating possible Lynch syndrome is beyond the scope of this review and has been recently addressed (25). The most accurate and confident diagnosis of Lynch syndrome is made by a positive genetic test result. However, a positive family history that meets Amsterdam criteria plus tumor analysis showing MSI should also be considered sufficient for the diagnosis. In contrast, families who fulfill Amsterdam criteria but do not have evidence of MSI appear to represent a separate entity. For the time being, the term "familial colorectal cancer type $X$ " has been suggested to distinguish them from Lynch families (29).

Table I. Amsterdam I and II Criteria and Bethesda Guidelines

Amsterdam / criteria

At least three relatives with colorectal cancer:

1. One is a first-degree relative of the other two

2. At least two successive generations should be affected

3. At least one colorectal cancer case diagnosed before age 50 years

4. Familial adenomatous polyposis has been excluded

\section{Amsterdam // criteria}

At least three relatives with a hereditary nonpolyposis colorectal cancer-associated cancer (colorectal cancer, endometrial, stomach, ovary, ureter/pelvis renal, brain, small bowel, biliary tract and skin -sebaceous tumors-)

1. One is a first-degree relative of the other two

2. At least two successive generations should be affected

3. At least one cancer case diagnosed before age 50 years

Bethesda criteria (revised 2004)

1. Colorectal cancer diagnosed before age 50 years

2. Presence of synchronous or metachronous colorectal cancer, or other HNPCC-related cancer* regardless of age

3. Colorectal cancer with MSI-H morphology (characterized by the presence of tumor infiltrating lymphocytes, mucinous/signet-ring differentiation, peritumoral Crohn's like lymphocytic reaction, or medullary growth pattern) before age 60 years

4. Colorectal cancer with one or more first-degree relatives with colorectal cancer or other HNPCC-related cancer, * one of the cancers before age 50 years

5. Colorectal cancer with two or more relatives with colorectal cancer or other HNPCC-related cancer* regardless of age

*Includes colorectal, endometrial, ovarian, gastric, small bowel, urinary tract, biliary tract, pancreas, brain, and sebaceous gland.

Unfortunately, genetic testing is not perfect. For example, a "negative" test result can be difficult to interpret. It is possible that genes other than those currently available for testing may be involved. Negative results are there- 
fore considered uninformative unless a mutation has been previously identified in an affected family member. Nevertheless, genetic testing is considered a standard of care in the management of hereditary colon cancer.

\section{TREATMENT}

\section{Surveillance for colon cancer}

Once a high-risk individual is recognized, management focuses primarily on strategies for risk reduction. Colonoscopy and prophylactic colectomy are the primary strategies to prevent colon cancer or detect it at an early stage.

The American Gastroenterology Association recommends annual sigmoidoscopy in patients with classic FAP and at-risk relatives starting at the age of 10-12 yr (30). Patients with adenomatous polyps on sigmoidoscopy should undergo full colonoscopy to establish the severity of polyposis.

A full colonoscopy is recommended annually in attenuated FAP patients starting from age 18-20 years, due to the tendency of colonic adenomas to be located proximally (31). It is reasonable to follow these recommendations in MAP patients beginning at the same age, but performing colonoscopy at 2-yearly intervals (31).

Individuals with Lynch syndrome should be offered colonoscopy every one to two years, beginning at the age of 20 to 25 years (age 30 years in families with MSH6 mutations), or ten years younger than the youngest age at diagnosis in the family (32) whatever comes first, and then annually after age 40 (33). Evidence of an accelerated rate of progression from adenoma to carcinoma coupled with the subtle endoscopic appearance of the typical flat adenomas and cancers in this syndrome serve as justifications for the short screening interval (34). CRC screening by means of colonoscopy and polypectomies in at-risk individuals for Lynch syndrome reduces CRC incidence by $62 \%$, prevents CRC deaths, and decreases overall mortality by about $65 \%$ in Lynch syndrome families (35).

\section{Surgical treatment in hereditary colon cancer syndromes}

In polyposis syndromes, surgery is the recommended approach for cancer prevention. Colectomy remains the optimal prophylactic treatment for FAP patients, which has been shown to increase survival by approximately three decades compared with undiagnosed FAP patients (36). However, the choice of procedure remains controversial. Surgical options include a total proctocolectomy (TPC) with permanent ileostomy, a total proctocolectomy with ileal pouch anal anastomosis (IPAA), or a subtotal colectomy with ileorectal anastomosis (IRA) (2).
TPC with permanent ileostomy is rarely chosen as a primary procedure, but it is justified under certain conditions: presence at diagnosis of an invasive cancer involving the distal rectum, when IPAA or IRA is not technically feasible because of desmoids, and based on patients preferences in terms of lifestyle (4).

The key in deciding between an IPAA and an IRA is the rectal polyp burden and subsequent risk of rectal cancer. If at the time of diagnosis, there is diffuse polyposis in the rectum, an IPAA procedure is recommended. More difficult to decide is the scenario when there is not much rectum involved at the time of surgery. The location of the APC germline mutation was proposed for surgical decision making, but this information is not always available at the time of surgery, nor does a perfect correlation between genotype and phenotype exist. Recently, the presence of fewer than 10 rectal polyps at presentation has been shown to be a good predictor of a favorable outcome after IRA (37).

Other factors that should be taken into account are fertility and desmoid development. Studies reported that fertility was significantly reduced after IPAA compared to IRA in women with FAP (38). Therefore, in young women who wish to have children, an IPAA should be avoided or postponed if it is possible (31). In patients with an increased risk of desmoid development (patients with a positive family history for these lesions or patients with a mutation located distal to codon 1444) a primary IPAA might be the best option. In these patients the conversion of IRA to IPAA might be very difficult due to mesenteric desmoid tumors and shortening of the mesentery (31).

Because functional results are fairly similar for IRA and IPAA (39) and the estimated cumulative risk of rectal cancer when the rectum is left is $10 \%$ at the age of 50 years and $29 \%$ by the age of 60 years (40), IPAA is generally preferred. However, the risk of cancer after IPAA procedure is not entirely eliminated. Neoplasia may occur along the rectal cuff at the site of ileal pouch anastomosis, and the frequency appears to be greater after stapled anastomosis (range, 28\% to 31\%) than after mucosectomy and hand-sewn anastomosis (range, 10\% to $14 \%)(41,42)$. Therefore, regardless of the procedure, close lifetime surveillance of the remaining rectum after IRA every 3-6 months is required, or the ileal pouch and rectal cuff after IPAA every 6-12 months (31).

There are no guidelines regarding the timing of surgery. In most cases, surgery is indicated if there are large numbers of adenomas $>5 \mathrm{~mm}$, including adenomas showing a high degree of dysplasia. Most patients with classical FAP undergo surgery between age 15 and 25 years (31).

Special consideration deserves patients with an attenuated polyposis phenotype and a strong family history for aggressive abdominal desmoid disease. Since abdominal trauma is associated with desmoids develop, delayed prophylactic colectomy while colonic polyp burden is controlled by polypectomy is preferred (43). 
The high frequency of colorectal cancer observed in the MYH-associated polyposis syndrome suggests that prophylactic colectomy may also be indicated. The choice between an IPAA and an IRA procedure can be based upon the number of rectal polyps at diagnosis, as in FAP $(31,37)$.

Prophylactic subtotal colectomy with IRA in Lynch syndrome patients should be considered in individuals who are known mutation carriers and have recurrent adenomas with a high degree of dysplasia or a villous growth pattern or adenomas that are endoscopically unresectable (27). In known mutation carriers without any colorectal adenomas, screening colonoscopy appears to be the most reasonable choice (32). However, prophylactic subtotal colectomy remains an option for patients who have significant anxiety about cancer risk or concern about safety of repeated colonoscopy or are unable to undergo periodic surveillance colonoscopy (27).

For those patients who will undergo surgical resection of a diagnosed colon cancer, subtotal colectomy instead of segmental resection is recommended due to the high risk of metachronous tumors $(40 \%$ at 10 years) $(27,44)$. No data are yet available to demonstrate that this surgical procedure is superior to intensive colonoscopic surveillance after segmental resection, although mathematical models have suggested an advantage for the more radical procedure especially in younger individuals with earlystage cancers (45).

The risk of rectal cancer in Lynch syndrome patients after subtotal colectomy is estimated at $12 \%$ at 12 years, so annual surveillance of the rectum should be performed (46).

\section{Chemoprevention of colon cancer}

Several studies have demonstrated that regular use of nonsteroidal anti-inflammatory drugs (NSAIDs) and selective COX-2 inhibitors can reduce polyp number and size in patients with FAP.

Regression of colorectal adenomas with sulindac (a nonsteroidal anti-inflamatory drug) has been demonstrated feasible, reducing the number of polyps to $44 \%$ of base-line values and the diameter of the polyps to $35 \%$ of base-line values after 9 months of treatment, but this effect was maintained over short follow-up periods $(\leq 1$ year) (47). Sulindac therapy is recommended in FAP patients after subtotal colectomy with IRA (48). However, rectal cancer has developed in patients in whom rectal polyps were effectively controlled with sulindac (49-51). In addition, sulindac appears to lack significant benefit in regressing duodenal adenomas (52) or preventing initial occurrence of adenomas in APC mutation carriers (primary prevention) (53). Thus, it cannot be considered as a reasonable alternative to surgery in FAP patients.

Celecoxib, a selective COX-2 inhibitor, has also shown a significant reduction $(28 \%)$ in the number of colorectal polyps at the dose of $800 \mathrm{mg} /$ day after six months of treatment (54). The same dose of celecoxib significantly reduces the number of duodenal polyposis (by $14.5 \%$ in the overall population and $31 \%$ in patients with more than $5 \%$ of their duodenal area covered with polyps at baseline) (55). In addition, rofecoxib has been demonstrated effective in maintaining the colon free of polyps in polyposis patients after endoscopic removal of all visible adenomas (56). However, significant cardiovascular side effects associated with these drugs limit their use as chemopreventive agents.

The efficacy of NSAIDs in Lynch syndrome is unknown. Biological evidence indicates that Lynch-associated tumors express lower levels of COX-2, suggesting that chemoprevention with NSAIDs or COX-2 inhibitors may be less effective (57). Also, it has been demonstrated lately that sulindac induces an increase in epithelial cell proliferation in the proximal colon of subjects with HNPCC (58). Since colorectal cancer predominantly arises in the proximal colon in HNPCC, these results shed doubts on the potential chemopreventive effects of sulindac in HNPCC.

\section{Extracolonic tumor surveillance}

In FAP patients, the cumulative risk ( $43 \%$ at the age of $60 \mathrm{yr}$ and $50 \%$ at the age of $70 \mathrm{yr}$ ) (59) of developing advanced duodenal adenomas (Spigelman's stage IV) (Table II) supports the importance of routine upper endoscopic surveillance. Although only about $5-10 \%$ of FAP patients are estimated to progress to duodenal cancer $(10,11,60)$, the prognosis after surgery for established tumor is poor (61-63). Moreover, an increase in severity of duodenal adenomatosis (due to an increasing number and size of adenomas) with age has been shown (10). Therefore, the aim of endoscopic surveillance is to identify patients at greatest risk of duodenal cancer and to intervene before an invasive tumor develops and when disease is at a potentially curable stage.

Table II. Spigelman classification for duodenal polyposis in FAP

\begin{tabular}{lccc}
\hline Criterion & 1 point & 2 points & 3 points \\
\hline Polyp number & $1-4$ & $5-20$ & $>20$ \\
Polyp size $(\mathrm{mm})$ & $1-4$ & $5-10$ & $>10$ \\
Histology & Tubular & Tubulovillous & $\begin{array}{c}\text { Villous } \\
\text { Dysplasia }\end{array}$ \\
Mild* & Moderate* & Severe** \\
\hline
\end{tabular}

Stage 0: 0 points; stage I: 1-4 points; stage II: 5-6 points; stage III: 7-8 points; stage IV: 9-12 points.

*a low degree of dysplasia according to current classification; **a high degree of dysplasia.

Because nearly two-thirds of duodenal adenomas occur in the papilla or periampullary region (64) and up to $12 \%$ of duodenal adenomas are indeed microadeno- 
mas without visible lesions (10), upper endoscopy with side-viewing endoscopes and systematic biopsies of the duodenal papilla are essential. Surveillance should begin in the mid 20's (or 5 years earlier than the youngest case of advanced duodenal adenomatosis in the family) and be repeated every 1-3 years depending on polyp burden.

The management of duodenal polyps remains a challenge, with different opportunities for endoscopical, surgical and pharmacological therapy. Prophylactic pancreaticoduodenectomy, either Whipple's operation or pylorus-sparing procedure, is the most hazardous election with procedural mortality rates estimated around 5\% (65). However, at least two reports of the larger series indicated that pre-operative polyposis staging might underestimate disease severity $(66,67)$. Carcinoma was found in 30 and $50 \%$ of the patients undergoing theoretically prophylactic surgery in those series. Hence, surgical referral should be considered for the high-risk group (Spigelman's stage IV). Rapidly growing lesions and periampullary adenomas in patients over $35-40 \mathrm{yr}$ of age, particularly if there is a family history of duodenal cancer should also be referred to surgery (67).

Endoscopic management of duodenal adenomatosis attracts increasing interest. Return to normal histology (34\%) and downgrading in the Spigelman stage III and IV in either periampullary or extra-ampullary adenomas have been reported $(68,69)$. However, only longer-term follow up will determine whether repeated endoscopic intervention, either alone or in combination with pharmacological therapy, may be offer to selected patients.

The prevalence of thyroid cancer (12\%), particularly in female FAP patients, might be higher than previously considered. Screening with thyroid ultrasound allows detection of small tumors (12), and annual thyroid ultrasound starting at age 18 years should be considered.

Thus far, there are no data demonstrating an effect of endometrial cancer screening upon morbidity and mortality in women with Lynch syndrome. However, because the lifetime risk of endometrial cancer is high, consideration of screening in this high-risk population is recommended. Thus, women at risk should be offered annual endometrial biopsy and annual transvaginal ultrasound starting at age 30 to 35 years. In addition, this procedure may be useful in ovarian cancer screening (32). Prophylactic total abdominal hysterectomy with bilateral salpingo-oopherectomy (TAHBSO) should be considered in patients whose childbearing is complete, especially when there is endometrial cancer in the family (70). The optimal timing of prophylactic surgery is unclear. Some experts recommend that TAHBSO should be offered to patients who have Lynch syndrome and will undergo surgery for CRC resection (32).

There are no data to support additional surveillance in Lynch syndrome patients, and specific recommendations are typically based upon the specific family history of cancer. Lately, the European group has recommended gastric cancer surveillance in Lynch syndrome families in countries with a high incidence of such tumor (27). Moreover, urinalysis, urine cytology, upper gastrointestinal tract endoscopy and abdominal ultrasound have been advocated by several experts (32).

\section{Family counseling}

Diagnosis of a genetic disorder has implications for many family members, especially in inherited cancer syndromes. Genetic testing may reduce cancer risk through effective medical procedures. Once a pathogenic mutation has been identified in an affected individual, atrisk relatives can be tested for that same mutation with virtually $100 \%$ accuracy.

FAP and Lynch syndrome are inherited in an autosomal dominant manner. Therefore, first degree relatives are at $50 \%$ risk of inheriting the mutation. The majority of individuals have inherited the mutation from a parent. However, if clinical and family history cannot identify from which parent the proband inherited the alteration, molecular genetic testing should be offered to both parents to determine which one has the gene mutation. Siblings and offspring of a proband should be offered genetic testing.

Due to the autosomal recessive pattern of inheritance in MAP syndrome, proband siblings will have a $25 \%$ risk of also having biallelic mutations and thus they should be considered for genetic testing. Because children of the proband are obligatory carriers, it may be reasonable to screen partner's proband to determine the risk of MAP in any future children (71).

\section{REFERENCES}

1. Colomer R. Cifras del cáncer en España. SEOM. El Mundo 2-22009.

2. Betes-Ibañez M, Carreto Ribón C, Muñoz-Navas M. Evidencia científica en cribado del cáncer colorrectal. Madrid: IM\&C S.A.; 2006.

3. Lynch HT, Lynch JF, Lynch PM, Attard T. Hereditary colorectal syndromes: molecular genetics, genetic counselling, diagnosis and management. Fam Cancer 2008; 7: 27-39.

4. Al-Sukhni W, Aronson M, Gallinger S. Hereditary colorectal cancer syndromes: familial adenomatous polyposis and Lynch syndrome. Surg Clin North Am 2008; 88: 819-44.

5. Cetta F, Dhamo A. Inherited multitumoral syndromes including colorectal carcinoma. Surg Oncol 2007; 16: S17-S23.

6. Groden J, Thliveris A, Samowitz W, Carlson M, Gelbert L, Albertsen $\mathrm{H}$, et al. Identification and characterization of the familial adenomatous polyposis coli gene. Cell 1991; 66: 589-600.

7. Aretz S, Uhlhaas S, Caspari R, Mangold E, Pagenstecher C, Propping $\mathrm{P}$, et al. Frequency and parental origin of the novo APC mutations in familial adenomatous polyposis. Eur J Hum Genet 2004; 12:52-8.

8. Aretz S, Stienen D, Friedrichs N, Stemmler S, Uhlhaas S, Rahner N, et al. Somatic APC mosaicism: a frequent cause of familial adenomatous polyposis (FAP). Hum Mutat 2007; 28 :985-92.

9. Hes FJ, Nielsen M, Bik EC, Konvalinka D, Wijnen JT, Bakker E, et al. Somatic APC mosaicism: an underestimated cause of polyposis coli. Gut 2008; 57: 71-6. 
10. Bulow S, Bjork J, Christensen IJ, Fausa O, Jarvinen H, Moesgaard F, et al. Duodenal adenomatosis in familial adenomatous polyposis. Gut 2004; 53: 381-6.

11. Bjork J, Akerbrant H, Iselius L, Bergman A, Engwall Y, Wahlstrom $\mathrm{J}$, et al. Periampullary adenomas and adenocarcinomas in familial adenomatous polyposis: cumulative risks and APC gene mutations. Gastroenterology 2001; 121: 1127-35.

12. Herraiz M, Barbesino G, Faquin W, Chan-Smutko G, Patel D, Shannon KM, et al. Prevalence of thyroid cancer in familial adenomatous polyposis syndrome and the role of screening ultrasound examinations. Clin Gastroenterol Hepatol 2007; 5: 367-73.

13. Bertario L, Russo A, Sala P, Eboli M, Giarola M, D'Amico F, et al Genotype and phenotype factors as determinants of desmoid tumors in patients with familial adenomatous polyposis. Int J Cancer 2001; 95: 102-7.

14. Arvanitis ML, Jagelman DG, Fazio VW, Lavery IC, McGannon E. Mortality in patients with familial adenomatous polyposis. Dis Colon Rectum 1990; 33: 639-42.

15. Sturt NJ, Gallagher MC, Bassett P, Philp CR, Neale KF, Tomlinson IP, et al. Evidence for genetic predisposition to desmoid tumours in familial adenomatous polyposis independent of the germline APC mutation. Gut 2004; 53: 1832-6.

16. Sieber OM, Lipton L, Crabtree M, Heinimann K, Fidalgo P, Phillips RK, et al. Multiple colorectal adenomas, classic adenomatous polyposis, and germ-line mutations in MYH. N Engl J Med 2003; 348: 791-9.

17. Sampson JR, Dolwani S, Jones S, Eccles D, Ellis A, Evans DG, et al. Autosomal recessive colorectal adenomatous polyposis due to inherited mutations of MYH. Lancet 2003; 362: 39-41.

18. Jenkins MA, Croitoru ME, Monga N, Cleary SP, Cotterchio M, Hopper JL, et al. Risk of colorectal cancer in monoallelic and biallelic carriers of MYH mutations: a population-based case-family study. Cancer Epidemiol Biomarkers Prev 2006; 15: 312-4.

19. Bouguen G, Manfredi S, Blayau M, Dugast C, Buecher B, Bonneau $\mathrm{D}$, et al. Colorectal adenomatous polyposis associated with $\mathrm{MYHmu}-$ tations: genotype and phenotype characteristics. Dis Colon Rectum 2007.

20. Nielsen M, Franken PF, Reinards TH, Weiss MM, Wagner A, van der Klift $\mathrm{H}$, et al. Multiplicity in polyp count and extracolonic manifestations in 40 Dutch patients with MYH associated polyposis coli (MAP). J Med Genet 2005; 42: e54.

21. Lynch HT, de la Chapelle A. Hereditary colorectal cancer. N Engl J Med 2003; 348: 919-32.

22. Hampel H, Stephens JA, Pukkala E, Sankila R, Aaltonen LA, Mecklin JP, et al. Cancer risk in hereditary nonpolyposis colorectal cancer syndrome: later age of onset. Gastroenterology 2005; 129: 41521.

23. Vasen HF, Wijnen JT, Menko FH, Kleibeuker JH, Taal BG, Griffioen $\mathrm{G}$, et al. Cancer risk in families with hereditary nonpolyposis colorectal cancer diagnosed by mutation analysis. Gastroenterology 1996; 110: 1020-7.

24. Aaltonen LA, Peltomaki P, Leach FS, Sistonen P, Pylkkanen L, Mecklin JP, et al. Clues to the pathogenesis of familial colorectal cancer. Science 1993; 260: 812-6.

25. Lynch HT, Boland CR, Rodriguez-Bigas MA, Amos C, Lynch JF, Lynch PM. Who should be sent for genetic testing in hereditary colorectal cancer syndromes? J Clin Oncol 2007; 25: 3534-42.

26. Lynch HT, de la Chapelle A. Genetic susceptibility to non-polyposis colorectal cancer. J Med Genet 1999; 36: 801-18.

27. Vasen HFA, Möslein G, Alonso A, Bernstein I, Beratio L, Blanco I, et al. Guidelines for the clinical management of Lynch syndrome (hereditary non-polyposis cancer). J Med Genet 2007; 44: 353-62.

28. Desai TK, Barkel D. Syndromic colon cancer: Lynch syndrome and familial adenomatous polyposis. Gastro Clin North Am 2008; 88: 819-44.

29. Lindor NM, Rabe K, Petersen GM, Haile R, Casey G, Baron J, et al. Lower cancer incidence in Amsterdam-I criteria families without mismatch repair deficiency: familial colorectal cancer type X. JAMA 2005; 293: 1979-85.

30. Winawer S, Fletcher R, Rex D, Bond J, Burt R, Ferrucci J, et al. Colorectal cancer screening and surveillance: clinical guidelines and rationale-Update based on new evidence. Gastroenterology 2003; 124 : $544-60$.
31. Vasen HFA, Möslein G, Alonso A, Aretz S, Bernstein I, Bertario L, et al. Guidelines for the clinical management of familial adenomatous polyposis (FAP). Gut 2008; 57: 704-13.

32. Lindor NM, Petersen GM, Hadley DW, Kinney AY, Miesfeldt S, Lu $\mathrm{KH}$, et al. Recommendations for the care of individuals with an inherited predisposition to Lynch syndrome: a systematic review. JAMA 2006; 296: 1507-17.

33. Guillem JG, Wood WC, Moley JF, Berchuck A, Karlan BY, Mutch $\mathrm{DG}$, et al. ASCO/SSO review of current role of risk-reducing surgery in common hereditary cancer syndromes. J Clin Oncol 2006;2 4: 4642-60.

34. Dove-Edwin I, Sasieni P, Adams J, Thomas HJ. Prevention of colorectal cancer by colonoscopic surveillance in individuals with a family history of colorectal cancer: 16 year, prospective, follow-up study. BMJ 2005; 331: 1047 .

35. Jarvinen HJ, Aarnio M, Mustonen H, Aktan-Collan K, Aaltonen LA, Peltomaki P, et al. Controlled 15-year trial on screening for colorectal cancer in families with hereditary nonpolyposis colorectal cancer. Gastroenterology 2000; 118: 829-34.

36. Nugent KP, Spigelman AD, Phillips RK. Life expectancy after colectomy and ileorectal anastomosis for familial adenomatous polyposis. Dis Colon Rectum 1993; 36:1059-62.

37. Valanzano R, Ficari F, Curia MC, Aceto G, Veschi S, Cama A, et al. Balance between endoscopic and genetic information in the choice of ileorectal anastomosis for familial adenomatous polyposis. J Surg Oncol 2007; 95: 28-33.

38. Olsen KO, Juul S, Bülow S, Järvinen HJ, Bakka A, Björk J, et al. Female fecundity before and after operation for familial adenomatous polyposis. Br J Surg 2003; 90: 227-31

39. Ambroze WL, Jr., Dozois RR, Pemberton JH, Beart RW, Jr., Ilstrup DM. Familial adenomatous polyposis: results following ileal pouchanal anastomosis and ileorectostomy. Dis Colon Rectum 1992; 35: $12-5$.

40. Nugent KP, Phillips RK. Rectal cancer risk in older patients with familial adenomatous polyposis and an ileorectal anastomosis: a cause for concern. Br J Surg 1992; 79: 1204-6.

41. van Duijvendijk P, Vasen HF, Bertario L, Bulow S, Kuijpers JH, Schouten WR, et al. Cumulative risk of developing polyps or malignancy at the ileal pouch-anal anastomosis in patients with familial adenomatous polyposis. J Gastrointest Surg 1999; 3: 325-30.

42. Remzi FH, Church JM, Bast J, Lavery IC, Strong SA, Hull TL, et al. Mucosectomy vs. stapled ileal pouch-anal anastomosis in patients with familial adenomatous polyposis: functional outcome and neoplasia control. Dis Colon Rectum 2001; 44: 1590-6.

43. Speake D, Evans DG, Lalloo F, Scott NA, Hill J. Desmoid tumours in patients with familial adenomatous polyposis and desmoid region adenomatous polyposis coli mutations. Br J Surg 2007; 94: 1009-13

44. Fitzgibbons RJ, Jr., Lynch HT, Stanislav GV, Watson PA, Lanspa SJ, Marcus JN, et al. Recognition and treatment of patients with hereditary nonpolyposis colon cancer (Lynch syndromes I and II). Ann Surg 1987; 206: 289-95.

45. de Vos tot Nederveen Cappel WH, Buskens E, van Duijvendijk P, Cats A, Menko FH, Griffioen G, et al. Decision analysis in the surgical treatment of colorectal cancer due to a mismatch repair gene defect. Gut 2003; 52: 1752-5.

46. Rodriguez-Bigas MA, Vasen HF, Pekka-Mecklin J, Myrhoj T, Rozen $\mathrm{P}$, Bertario L, et al. Rectal cancer risk in hereditary nonpolyposis colorectal cancer after abdominal colectomy. International Collaborative Group on HNPCC. Ann Surg 1997; 225: 202-7.

47. Giardiello FM, Hamilton SR, Krush AJ, Piantadosi S, Hylind LM, Celano P, et al. Treatment of colonic and rectal adenomas with sulindac in familial adenomatous polyposis. N Engl J Med 1993; 328: 1313-6.

48. Lynch PM. Chemoprevention with special reference to inherited colorectal cancer. Fam Cancer 2007.

49. Tonelli F, Valanzano R, Messerini L, Ficari F. Long-term treatment with sulindac in familial adenomatous polyposis: is there an actual efficacy in prevention of rectal cancer? J Surg Oncol 2000; 74: 15-20.

50. Cruz-Correa M, Hylind LM, Romans KE, Booker SV, Giardiello FM. Long-term treatment with sulindac in familial adenomatous polyposis: a prospective cohort study. Gastroenterology 2002; 122: 641-5. 
51. Lynch HT, Thorson AG, Smyrk T. Rectal cancer after prolonged sulindac chemoprevention. A case report. Cancer 1995; 75: 936-8.

52. Richard CS, Berk T, Bapat BV, Haber G, Cohen Z, Gallinger S. Sulindac for periampullary polyps in FAP patients. Int J Colorectal Dis 1997; 12: 14-8.

53. Giardiello FM, Yang VW, Hylind LM, Krush AJ, Petersen GM, Trimbath JD, et al. Primary chemoprevention of familial adenomatous polyposis with sulindac. N Engl J Med 2002; 346: 1054-9.

54. Steinbach G, Lynch PM, Phillips RK, Wallace MH, Hawk E, Gordon $\mathrm{GB}$, et al. The effect of celecoxib, a cyclooxygenase-2 inhibitor, in familial adenomatous polyposis. N Engl J Med 2000; 342: 1946-52.

55. Phillips RK, Wallace MH, Lynch PM, Hawk E, Gordon GB, Saunders BP, et al. A randomised, double blind, placebo controlled study of celecoxib, a selective cyclooxygenase 2 inhibitor, on duodenal polyposis in familial adenomatous polyposis. Gut 2002; 50: 857-60.

56. Hallak A, Alon-Baron L, Shamir R, Moshkowitz M, Bulvik B, Brazowski E, et al. Rofecoxib reduces polyp recurrence in familial polyposis. Dig Dis Sci 2003; 48: 1998-2002.

57. Sinicrope FA, Lemoine M, Xi L, Lynch PM, Cleary KR, Shen Y, Frazier ML. Reduced expression of cyclooxygenase 2 proteins in hereditary nonpolyposis colorectal cancers relative to sporadic cancers. Gastroenterology 1999; 117: 350-8.

58. Rijcken FE, Hollema H, van der Zee AG, van der Sluis T, Boersmavan Ek W, Kleibeuker JH. Sulindac treatment in hereditary non-polyposis colorectal cancer. Eur J Cancer 2007; 43: 1251-6.

59. Saurin JC, Gutknecht C, Napoleon B, Chavaillon A, Ecochard R, Scoazec JY, et al. Surveillance of duodenal adenomas in familial adenomatous polyposis reveals high cumulative risk of advanced disease. J Clin Oncol 2004; 22: 493-8

60. Jagelman DG, DeCosse JJ, Bussey HJ. Upper gastrointestinal cancer in familial adenomatous polyposis. Lancet 1988; 1: 1149-51.

61. Beckwith PS, van Heerden JA, Dozois RR. Prognosis of symptomatic duodenal adenomas in familial adenomatous polyposis. Arch Surg 1991; 126: 825-7; discussion 827-8.
62. Penna C, Bataille N, Balladur P, Tiret E, Parc R. Surgical treatment of severe duodenal polyposis in familial adenomatous polyposis. Br J Surg 1998; 85: 665-8.

63. Groves CJ, Saunders BP, Spigelman AD, Phillips RK. Duodenal cancer in patients with familial adenomatous polyposis (FAP): results of a 10 year prospective study. Gut 2002; 50: 636-41.

64. Bertoni G, Sassatelli R, Nigrisoli E, Pennazio M, Tansini P, Arrigoni A, et al. High prevalence of adenomas and microadenomas of the duodenal papilla and periampullary region in patients with familial adenomatous polyposis. Eur J Gastroenterol Hepatol 1996; 8: 12016.

65. Neoptolemos JP, Russell RC, Bramhall S, Theis B. Low mortality following resection for pancreatic and periampullary tumours in 1026 patients: UK survey of specialist pancreatic units. UK Pancreatic Cancer Group. Br J Surg 1997; 84: 1370-6.

66. Gallagher MC, Shankar A, Groves CJ, Russell RC, Phillips RK. Pylorus-preserving pancreaticoduodenectomy for advanced duodenal disease in familial adenomatous polyposis. Br J Surg 2004; 91: 1157 64.

67. Kadmon M, Tandara A, Herfarth C. Duodenal adenomatosis in familial adenomatous polyposis coli. A review of the literature and results from the Heidelberg Polyposis Register. Int J Colorectal Dis 2001; 16: 63-75.

68. Norton ID, Geller A, Petersen BT, Sorbi D, Gostout CJ. Endoscopic surveillance and ablative therapy for periampullary adenomas. Am J Gastroenterol 2001; 96: 101-6.

69. Gallagher MC, Phillips RK, Bulow S. Surveillance and management of upper gastrointestinal disease in familial adenomatous polyposis. Fam Cancer 2006; 5: 263-73.

70. Schmeler KM, Lynch HT, Chen LM, Munsell MF, Soliman PT, Clark MB, et al. Prophylactic surgery to reduce the risk of gynecologic cancers in the Lynch syndrome. N Engl J Med 2006; 354: 261-9.

71. Kaz AM, Brentnall TA. Genetic testing for colon cancer. Nat Clin Pract Gastroenterol Hepatol 2006; 3: 670-9. 